\title{
DEVELOPMENT OF METHODOLOGY AND TOOLS FOR COMPARATIVE ASSESSMENT OF OPERATIONAL EFFICIENCY OF KPI-BASED LOGISTICAL INFRASTRUCTURE FACILITIES
}

\author{
V. S. Lukinskiy, ${ }^{1}$ M. M. Pimonenko², M. Paajanen ${ }^{3}$, T. G. Shulzhenko ${ }^{4}$ \\ ${ }^{1}$ Saint-Petersburg State University of Economics \\ Sadovaya str., 21, Saint-Petersburg, 191023, Russia \\ E-mail: dept.kliop@engec.ru \\ ${ }^{3}$ Aalto University \\ Helsinki, Finland \\ E-mail:malla.paajanen@aalto.fi \\ ${ }^{2,4}$ North-Western Russian Logistics Development and Information Centre ILOT \\ Bukharestskaya str. 25, ap.63, Saint-Petersburg, 192242, Russia \\ E-mail:pimw@wnet.ru
}

\begin{abstract}
The article features an approach to comparative assessments of logistics centres operational efficiency based on the system of logistics key performance indicators and describes the framework methodology and the order for the development of the methodological support of the specified task.

The study was conducted in the framework of the Rail Baltica Growth Corridor (RBGC) Russia project, which seeks to involve North-West Russia in the dialogue about Rail Baltica transport corridor and is supported by the Delegation of the European Union to Russia for the period 2012-2013. Particularly, RBGC Russia addresses the issues of operational and functional interoperability of logistics centres in Eastern Baltic Sea Region.
\end{abstract}

Keywords: assessment of efficiency, logistics activity, terminal and logistics complexes, key performance indicators of logistics activity (KPI), general logistical costs model

\section{Introduction}

New requirements for the applied logistics technologies used to manage the systems of different levels are imposed by the current economy trends, which are associated with the increase of national economies integration level, growing globalisation of various activities, formation of modern production and distribution systems, etc. Alongside with that, implementation and active use of these technologies implies that there is a high-technology and efficiently operating logistical infrastructure where, to our opinion, top priority should be given to establishing integrated systems of the infrastructure support based on the international projects on logistics infrastructure development which are expected to result as follows: growing intensity of the cross-border traffic flows, reduced logistical costs related to transit and interstate traffic flows, development of the intermodal delivery technologies, increase of the development level and operational efficiency of the warehouse component of the logistics infrastructure. We believe that the principles of integration and coordination of logistics centres operation should form the basis for successful implementation of such projects. Global experience evidence the importance of the logistics centres in providing coordination and interaction in the work of various means of transport, development of the intermodal cargo traffic and ensuring state-of-the-art logistics technologies being implemented. In this case the integration and coordination principles are implemented depending on the level of the development and operability both of the entire complex of the respective logistical infrastructure facilities and of the individual logistics centres.

In this regard a number of issues need to be resolved.

1. What are the state and development prospects of the logistical infrastructure in the region under consideration?

2. What is the methodological basis for the comparative assessment of the logistics centres operational efficiency? 
3. What indicators can most reasonably be used to get such estimates?

4. Which methods ensure obtaining the results which make it possible, on the one hand, to take into account the specific features of particular logistics centres' business processes and, on the other hand, to provide quantitative estimation of their impact upon general performance indicators, for example, the total logistical costs?

The following succession in solving the problems raised was applied within the Rail Baltica Growth Corridor project.

\section{Assessment of the State and Trends of the Terminal and Warehouse Services Market Development in the North-Western Region}

This problem was resolved in two stages:

- general analysis of Saint-Petersburg warehousing property market based on the published data provided for by the independent consulting and analysis agencies (ASTERA, Jones Lang Lasalle, Colliers International, Knight Frank Saint Petersburg, etc.);

- detailing features of the demand for high-quality warehouse spaces, stockpiling and handling services using polling techniques (including online questioning) and the subsequent interview.

According to the estimates given by the experts of analytical departments of independent consulting companies in respect of the warehousing property market, the warehousing property facilities of the North-Western region have managed to overcome the economic slowdown after-effect, and their indicators are gradually growing up.

The constantly growing demand for high-quality warehouse premises is taken into consideration when analysing the situation at the warehousing property market of the North-Western region. Increase in the demand for warehouse facilities may be observed both from perspective of small companies and major logistical market players. This causes severe reduction in the share of high-quality vacant warehouse premises. Increase in the demand for high-quality warehouse premises is promoted by the activities of the majority of the development companies which have chosen not to construct any facilities without prior agreements with customers. Currently the most popular type of warehousing property facilities is customer-paid warehouse complexes that are subject to "build-to-suit" conditions. Further rental rate growth has been promoted by the existing relation between the warehouse premises being placed in operation and those in demand.

At the end of the year 2012, the share of the vacant warehouse spaces in Saint-Petersburg was the lowest in recent 5 years. According to different analytical agencies, it has reduced to $2.2-4.9 \%$ (Fig. 1). At the same time the facilities declared to be commissioned in the coming years have not yet covered the existing deficit and the level of vacant spaces may decrease to terminal values. The year 2012 saw an $11 \%$ increase in the total scope of the speculative supply (the scope of the leased and leasable areas) at the Saint-Petersburg high-quality warehouse property market, which, according to different sources, makes from 1.07 to 1.85 million $\mathrm{m}^{2}$.

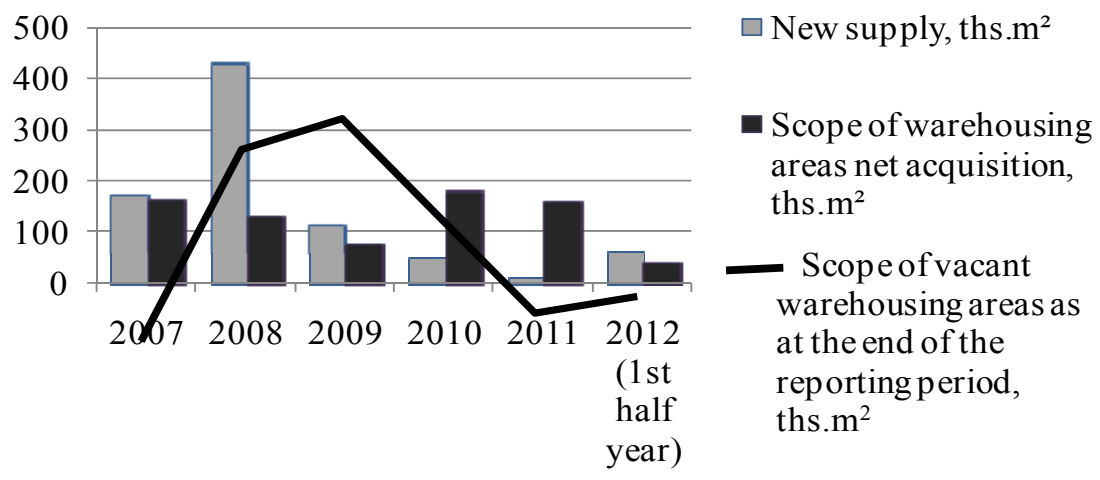

Figure 1. Level of vacant warehousing areas and their acquisition, Saint-Petersburg

In 2012 an aggregate net acquisition of the areas in the operating complexes made up about 150 ths. $\mathrm{m}^{2}$ showing a $4 \%$ decrease, compared to 2011 . Shortage of cost effective areas in the existing highclass warehouse complexes results in the leaseholders' demand being gradually reoriented to the operating facilities of lower class, to the new complexes under construction and industrial parks. The 
share of the vacant warehousing areas and rental rates have come back to 2006 level, when a great number of speculative projects started to be actively commissioned on the market.

The following changes have been recently recorded in the pattern of demand at the SaintPetersburg high-quality warehousing property market: the most active lease market participants are still trading companies and commercial and industrial companies renting the warehouse areas to arrange their own distribution centres (63\%). Logistics operators' share in the total demand pattern was reduced to $34 \%$, while the share of the manufacturing companies went down to $3 \%$. Construction companies, hardware suppliers and food industry enterprises are the most active players at the Saint-Petersburg warehousing property rental market. According to the data provided by Knight Frank Saint-Petersburg, in 2012 online trading distributors have accounted for about $80 \%$ of lease transactions on the SaintPetersburg warehousing property market.

Following the results of the examinations performed by the experts of major consulting agencies, the sales representatives of large hypermarkets, distributors and logistics operators are the key tenants in the high-quality warehouse complexes. The blocks of 3-5 ths. $\mathrm{m}^{2}$ are the most popular lease format. $56 \%$ of the total number of the recent warehousing property lease transactions is accounted for the transactions with an area of up to 5 ths. $\mathrm{m}^{2}$; in its turn $25 \%$ is accounted for transactions with an area over 10 ths. $\mathrm{m}^{2}$ and $19 \%$ - for transactions with an area from 5 to 10 ths. $\mathrm{m}^{2}$. At the same time the average size of the leased warehouse module tends to grow.

Table 1 represents basic indicators of the Saint-Petersburg warehousing property market.

Table 1. Warehousing property market indicators (Saint-Petersburg)

\begin{tabular}{|l|c|c|c|}
\hline Indicator & I quarter of 2008 & I quarter of 2009 & I quarter of 2012 \\
\hline Area in most high demand, $\mathrm{m}^{2}$ & $2000-4000$ & $500-2000$ & $3000-5000$ \\
\hline $\begin{array}{l}\text { Rental rate, USD } \\
\text { (net of operating expenses and VAT) }\end{array}$ & $128-208$ & $90-150$ & A: $120-130$ \\
\hline Lease agreement term & 3-7 years & B: $98-117$ \\
\hline Lease agreement currency & USD & Roubles & Roubles, Euro \\
\hline
\end{tabular}

A questionnaire was used to specify the characteristics of demand for high-quality warehouse spaces and stockpiling and handling services. The questionnaire includes 6 sections (26 questions): company's overall performance, financial indicators of a company's activity, assessment of the state and development prospects of the logistics services market, customer management, company's expected future development and information technologies.

Based on the estimates received, the companies involved in the questionnaire noted the general excess of supply over demand on the logistics services market. Rendering complex logistics services aimed primarily at the domestic market and at the limited number of large clients (1-3) is considered to be the business opportunities for the companies. The following is named as the areas of activity optimisation: selecting subcontractors, introducing information systems; according to the respondents, the potential threats can be: change of the legal framework in the field of logistics, shortage of financial resources and intensification of competition.

The results of the received data analysis make it possible to conclude that settling the problem how to make rational choice of the logistical infrastructure facilities (herein - terminal and logistics centres) when included into the project under development requires formation of tools for comparative assessment of operational efficiency thereof. The settlement of the task might be of interest, first of all, for supply chain prospective partners and for moderators of the projects related to the development of terminal and warehouse infrastructure, and only then for logistics centres themselves as in the circumstances where the facilities are occupied to the maximum possible extent the problems of in-depth analysis of business processes are not treated as topical by such companies. However, this situation seems temporary in our opinion; when the warehousing property market conditions change, affected, for example, by commissioning of the declared warehousing complexes or by the intensified competition at the warehousing services market, management of logistics centres will also require available tools to estimate how the decisions made affect general performance indicators of a facility and the supply chain.

\section{Analysis of the Existing Approaches to Formation of the Systems of Logistics Activity Assessment Indicator Systems}

Positive business results in aspects of the logistical strategy appear to be achievable when using Balanced Scorecard (BSC) as the key tool for analysing and regulating a company's activity. A widely 
used Balanced Scorecard concept is based on the requirement to consider in aggregate various business aspects - particularly, finances, clients, and processes, potential - to provide for the company's effectiveness assessment. But application of basic BSC ideas to logistics meets certain challenges as this concept was initially formed as an instrument for adequate evaluation of manufacturing companies' value using non-monetary indicators alongside with the traditional financial indicators. It stands to reason that composition of these indicators reflected the specific features of the enterprises under study and could not be applied without having been respectively revised and adapted to the assessment of the logistical activity. Thus, one of the primary tasks of BSC being used in logistics is related to forming a complex of the logistical activity's key performance indicators $(K P I)$. Settlement of this issue appears to be important as $K P I$ system is an effective means of controlling logistical business processes.

The analysis of the contemporary logistics sources enables to admit that by now there is not any universal viewpoint established in respect of the composition and the structure of the key estimated figures (indicators) of the logistics activity effectiveness. In particular, according to M.Christopher [1], the minimum set of indicators for logistics assessment includes estimation of the service quality (in respect of providing for the designated level of an "ideal (or perfect) order"), response time (according to the time spent to fulfil the order in the supply chain), general costs (according to costs for logistical service). J.Stock and D.Lambert [4] highlight four groups of key logistical indicators, including both quantitative and qualitative ones.

Scientific and study logistics materials represent other approaches to distinguishing the indicators of the logistical decisions efficiency for various logistical fields and logistical infrastructure facilities (for instance, [5], [6], [7]).

Summing up different approaches described in the course of the scientific discussion on the issue under consideration we believe that the key (or complex) indicators generally evaluating efficiency and effectiveness of logistics should include: total logistical costs (KPI-1), quality of logistical service $(K P I-2)$, logistical cycles duration $(K P I-3)$, productive capacity $(K P I-4)$, return on the investments in logistical infrastructure $(K P I-5)[2]$.

Alongside with that, there is a group of particular indicators included into the structure of the companies' logistics activity indicators which, in their turn, are divided into effectiveness indicators (Ple) and performance indicators (Pli). Figure 2 outlines the hierarchy of companies' logistical activity indicators.

\begin{tabular}{|c|c|}
\hline Balanced ScoreCard (BSC) of an enterprise & $\begin{array}{l}\text { 1) Financial results } \\
\text { 2) Order portfolio } \\
\text { 3) Domestic business processes } \\
\text { 4) Staff training and development }\end{array}$ \\
\hline \multicolumn{2}{|c|}{ Logistics General Indicators } \\
\hline Logistics key performance indicators (KPI) & $\begin{array}{l}\text { 1) General costs } \\
\text { 2) Logistical service quality } \\
\text { 3) Cycle execution time } \\
\text { 4) Productive capacity } \\
\text { 5) Investment application }\end{array}$ \\
\hline \multicolumn{2}{|c|}{ Logistics Specific Indicators } \\
\hline Effectiveness Indicators (Ple) & Performance Indicators (Pli) \\
\hline $\begin{array}{l}\text { 1) General logistical costs } \\
\text { 2) Costs associated with transportation in the } \\
\text { territory of a terminal and logistics center, } \\
\text { etc. }\end{array}$ & $\begin{array}{l}\text { 1) Number of orders processed per unit of } \\
\text { time } \\
\text { 2) Cargo shipments per unit of a terminal and } \\
\text { logistics center capacity, etc. }\end{array}$ \\
\hline
\end{tabular}

Figure 2. Hierarchy of a company's logistical activity indicators 


\section{Itemization of the Existing Approaches to Formation of Performance Indicator Systems as Applied to Terminals, Terminal Complexes and Warehouses}

Systems of key indicators estimating the warehouse activity are formed on the basis of the development (or description of the existing) materials handling business processes covering all component processes. It is evident that the described systems of business processes of different terminal and warehouse complexes are unique and determined by the accepted technological process of handling, specifics related to integration relations with arrival and departure transport and other elements of a supply chain. This reasons the variety of the developed KPI systems related to transformation of the traffic flows at the warehousing logistical infrastructure facilities.

\section{Selecting a Technique to Form Quantitative Estimates of How General Logistical Costs are Affected by the Work of Certain Logistics Centres}

Modern approaches to assessment of the logistics key indicators are mainly limited to application of the methods of comparison: with the reference standard (or absolute standards, i.e. the best results that can ever be achieved), with best practices (benchmarking), with targets, with past standards (the results that were achieved in the past periods). An obvious advantage of these approaches is their simplicity; however, they also have serious faults which prevent them from being put into practice. In particular, the method of comparing with the previous standards brings into focus the problem of data compatibility, the method of comparing with the targets requires that plan figure values should be estimated, benchmarking involves prior analysis of companies' logistical business processes. Moreover, the specified methods fail to provide the basis for KPI factorial analysis, therefore it is impossible to estimate the impact that the management decisions rendered have upon the effectiveness of the logistical system expressed in terms of the key estimates, which should be regarded as the most essential fault of comparison methods.

Elimination of the said drawbacks, reduction of the analysis terms, more complete coverage of the factors influencing business results, substitution of approximate or simplified calculation by exact computation may be achieved with the use of the integral method as one of the mathematical methods of the economic analysis. But the integral method application is connected with the search of the analytic dependence representing interrelation between arguments-factors and the resulting characteristic. In our opinion, the model of total logistical costs (TLC) can be accepted as such dependence as the formal representation of model (1) includes individual indicators of effectiveness (performance) and productive capacity of the logistics activity, which, in their turn, may be reduced to KPI total (key) indicators. Thus, the direction in which the analytic dependence should be searched is based on the statement of connection and interrelation of $T L C$ model and the key estimates of the KPI logistics activity.

$C_{\Sigma}=A C_{n}+\frac{A}{S} C_{0}+C_{n} f \frac{S}{2}+C_{n} f \sigma_{S} k_{p}+\frac{A}{S} C_{\partial} \sigma_{S} E(z)+\frac{A}{S} P\left(T_{0}<T\right) C_{u}$

where

$A$ - production requirement during the period under review;

$C_{\Pi}$ - price per unit of product;

$C_{0}-$ costs related to arrangement and execution of an order;

$S$ - order lot (delivery) size;

$f$-storage cost share depending on the price per unit of product;

$\sigma_{S}-$ standard deviation of the reserve stock;

$k_{p}$ - coefficient (parameter) corresponding to probability of shortage absence $P(S)$;

$C_{\partial}-$ losses caused by inventory shortage;

$E(z)$ - loss function (tabulated for normal law of distribution);

$z$ - safety factor;

$C_{u}$ - amount of fines paid for contractual terms infringement, for instance, for breach of the delivery schedule;

$P\left(T_{0}<T\right)$ - probability of contractual terms infringement, namely, of the delivery schedule.

Detailed representation of the structure of the total logistical costs model enabled to reveal strong interrelation with logistics key performance indicators (KPI). In particular, the total value of the logistical costs under model (1) is KPI-1 value, individual factors like "Costs for internal and external transportation", "Costs for stockpiling and materials handling", "Order procedure related costs", "Costs for stock management" are included into an equation of the total logistical costs (1). The similar analysis has been carried out for KPI-2 "Logistics service quality", KPI-3 "Duration of logistical cycles", KPI-5 "Return on logistical infrastructure investments". 


\section{Development of KPI-Based Analytical Tools to Assess the Activity of Terminal and Logistical Complexes}

The next stage is aimed at the development of the analytical tolls. An integral method of the economic analysis has been chosen as an applicable methodological framework. The analysis method has been adopted due to a number of reasons:

- the method makes it possible to determine the impact the indicators have on the function value at any number of arguments, any form of their connection and irrespective of the succession of factor analysis; it is also notable for high accuracy of computation;

- large-scale practical application thereof, as the use of the working formulas obtained during the analysis does not require the practitioners to know any source data required in the course of the mathematical transformation analysis.

Formation of the $K P I$-system for terminal and logistics complexes is based on the stage.

- by-stage decomposition of the structure of the total logistical costs model as regards the elements connected with implementation of stockpiling and handling functions. To do this it is necessary to itemize the total logistical costs model with transport and logistics operations at a terminal and logistics complex being taken into account. In this case the number of the model components and, therefore, the number of arguments-factors are obviously going to increase (Fig. 3).

To sum it up, the specifics of the proposed approach are as follows: the KPI composition may be considerably variable depending upon specifics of operational activities of the terminal and warehouse complex; at the same time, the total logistical costs model comprising different logistic functions (stock management, transportation, stockpiling and handling, etc.) being used as the basis allows to tie up interests of different companies forming the supply chain.

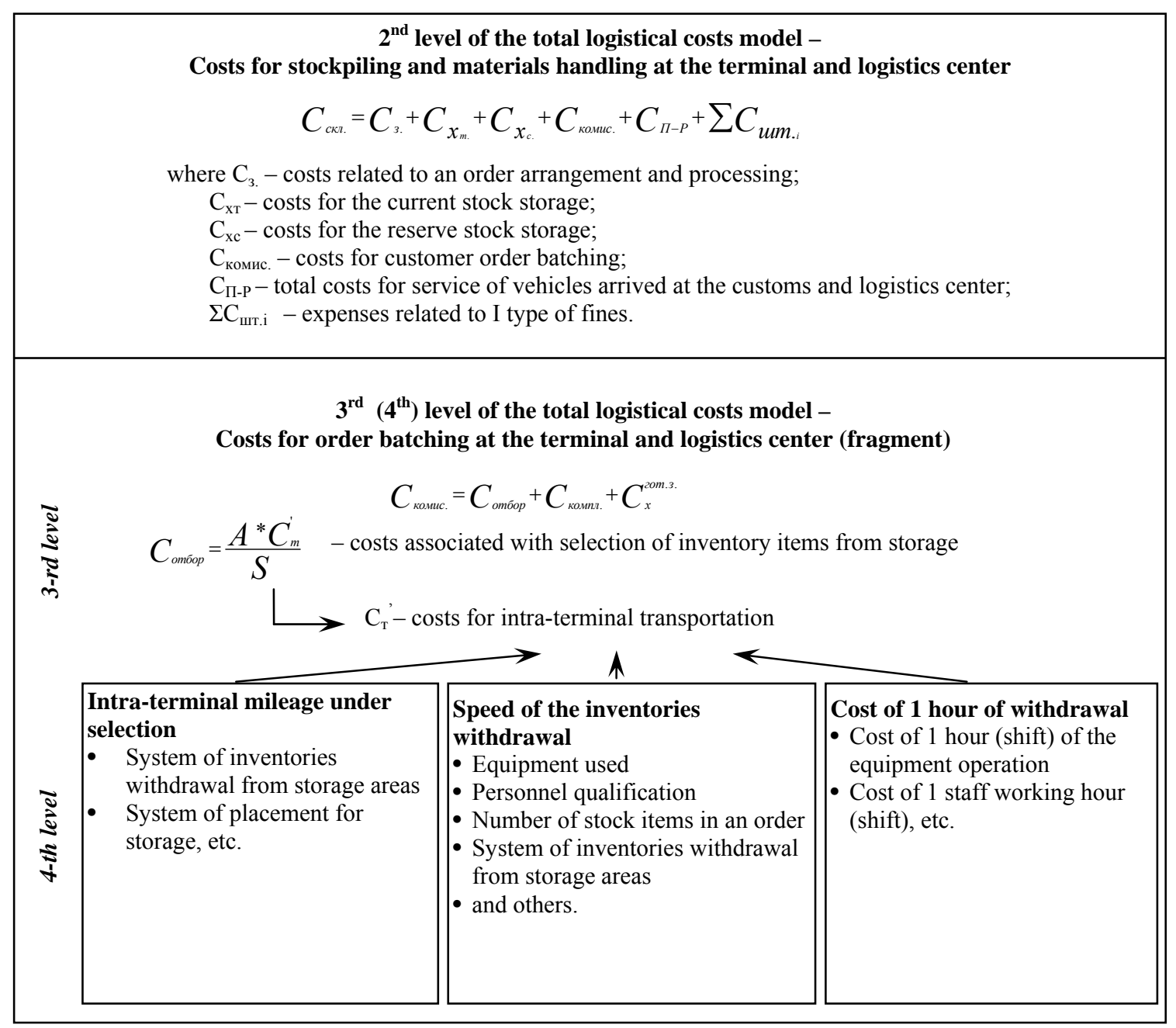

Figure 3. Itemization of the total logistics costs model for terminal and logistics centres (complexes) 


\section{References}

1. Christopher, M. (2005). Logistics and Supply Chain Management; V. S. Lukinsky (Ed.); translated from English. St. Petersburg: Piter.

2. Dybskaya, V. V., Zaitsev, E. I., Sergeev, V. I., Sterligova, A. N. (2008). Logistics: textbook; V. I. Sergeev (Ed.). M.: EKSMO.

3. Lukinsky, V. V., Shulzhenko, T.G., Markovich, M.A. (2011). Assessment of the Logistics Key Indicators Based on the Methods of Economic Analysis. In V.S. Lukinsky, a.o. (Eds.), Logistics: Current Development Trends: Materials of X International Research and Practice Conference, $14^{\text {th }}-15^{\text {th }}$ April, 2011 (pp. 217-219). Saint-Petersburg: Saint-Petersburg State University of Engineering and Economics.

4. Stock, J., Lambert, D.M. (2005). Logistics Strategic Management. M.: Infra-M.

5. Pilipchuk, S. F., Radaev, A. E. (December 2009). On the System of Warehousing Efficiency Indicators. Logistics and Supply Chain Management, 6(35), 40-53.

6. Tolmachev, K. (2008). Warehouse Complex Key Performance Indicators (KPI). Warehousing Technologies. Warehouse Management, 2, 29-37.

7. Fedorenko, A. I., Zelenov, N. N. (2010). Analysis of Port Activities Indicators. Today's Logistics, 5(41), 296-311. 